\title{
CONSULTA DE ENFERMAGEM ÀS PESSOAS COM ÚLCERAS DE PERNA E DOENÇA FALCIFORME: RELATO DE EXPERIÊNCIA
}

\author{
Laureana Oliveira da Silva ${ }^{1}$ \\ Aline Silva Gomes Xavier ${ }^{2}$ \\ Evanilda Souza de Santana Carvalho ${ }^{3}$ \\ Edna Maria de Araújo ${ }^{4}$
}

\begin{abstract}
RESUMO: Este relato descreve a consulta de enfermagem às pessoas com úlceras de perna e doença falciforme, realizada em atividades da extensão universitária, que contemplaram anamnese, exame físico e exame da ferida. Os bolsistas identificaram os diagnósticos de enfermagem e elaboraram planos de cuidados centrados no autocuidado. As medidas, sistematizadas por meio da consulta de enfermagem, nessa experiência, qualificaram o cuidado às pessoas com úlceras de perna e doença falciforme, resultando em conforto e melhoria na qualidade de vida desses enfermos. Esse resultado contribuiu para mudanças na rede de atenção, possibilitando a criação de espaço especializado de cuidado e revelando a potencialidade das atividades da extensão universitária para a mudança da realidade de grupos vulneráveis.
\end{abstract}

PALAVRAS-CHAVE: Enfermagem. Cuidados de Enfermagem. Anemia falciforme. Úlcera de perna.

\section{An experience report on nursing consultation with people with leg ulcers and sickle cell disease}

\begin{abstract}
This report describes the nursing consultation with people with leg ulcers and sickle cell disease developed in university extension activities. The consultation consisted of anamnesis, physical examination and wound assessment. The students identified nursing diagnosis and developed care plans centered care in self-care. Systematized measures through the nursing consultation qualified the care to people with leg ulcers and sickle cell disease, which resulted in a more comfortable and better quality of life of those people. This result contributed to changes in the care network, making possible the creation of specialized care space, revealing the potential of university extension activities of changing the reality of vulnerable groups.
\end{abstract}

KEYWORDS: Nursing. Nursing care. Sickle cell anemia. Leg ulcer.

\footnotetext{
${ }^{1}$ Graduanda em Enfermagem e bolsista de iniciação cientifica na Universidade Estadual de Feira de Santana (laureana.silva@hotmail.com).

2 Mestre em Enfermagem pela Universidade Federal da Bahia, professora assistente do Departamento de Saúde da Universidade Estadual de Feira de Santana, pesquisadora do Núcleo Interdisciplinar de Estudo sobre Desigualdade em Saúde (NUDES/UEFS) (asgx@ig.com.br).

${ }^{3}$ Doutora em Enfermagem pela Universidade Federal da Bahia, professora adjunta do Departamento de Saúde da Universidade Estadual de Feira de Santana, pesquisadora do Núcleo Interdisciplinar de Estudo sobre Desigualdade em Saúde (NUDES/UEFS) (evasscarvalho@yahoo.com.br).

${ }^{4}$ Doutora em Saúde Pública pelo Instituto de Saúde Pública da Universidade Federal da Bahia, professora titular do Departamento de Saúde da Universidade Estadual de Feira de Santana, pesquisadora e coordenadora do Núcleo Interdisciplinar de Estudos sobre Desigualdades em Saúde (NUDES/UEFS) (ednakam@gmail.com).
} 


\section{INTRODUÇÃO}

Doença falciforme (DF) é o conjunto de hemoglobinopatias hereditárias caracterizadas pela presença da hemoglobina $\mathrm{S}$. As manifestações clínicas da DF são resultantes da hemólise crônica ou trombose. Dentre os sintomas mais comuns estão crises dolorosas, ocasionadas pela hipóxia tissular e necrose decorrente do fluxo sanguíneo inadequado para uma região específica ou órgão, sendo as úlceras de perna uma das complicações (THOMAS, 2009).

Pessoas com DF e úlceras de perna convivem com dor intensa, mobilidade diminuída, longos tratamentos, além de perda da autonomia para realização de atividades diárias. Elas padecem de limitações no atendimento de suas demandas de cuidado, devido ao desconhecimento dos profissionais acerca desse tipo de complicação. A úlcera crônica depende do bem-estar geral da pessoa para alcance da cicatrização, exigindo do profissional uma abordagem integral.

As úlceras de perna estão entre as mais notórias manifestações cutâneas da DF, presentes entre 8 e $10 \%$ das pessoas com a doença, são mais comuns na anemia falciforme (HbSS) e menos frequentes na hemoglobina $\mathrm{C}(\mathrm{HbSC})$ e na talassemia (HbS- $\beta$-talassemia) (BRASIL, 2006). Podem se manifestar a partir dos 10 anos de idade, em uma ou em ambas as pernas, localizadas mais comumente nos maléolos laterais e mediais, sendo mais raras no dorso do pé e nas pernas. O aparecimento pode ser espontâneo ou consequente a algum trauma mecânico, e a cicatrização é lenta e com grande probabilidade de recidiva (PALADINO, 2007).

A DF é uma doença crônica, com a qual os pacientes irão conviver por toda a vida, sendo necessária a sua educação e de sua família para adesão ao tratamento e adoção do autocuidado, com vistas a uma melhor qualidade de vida. $\mathrm{O}$ autocuidado, isto é, o cuidado de si mesmo, visa às necessidades do corpo e da mente, melhoria do estilo de vida, eliminação de hábitos nocivos, adoção de alimentação saudável, conhecimento e controle dos fatores de risco que conduzem às doenças e prevenção delas (BRASIL, 2006).

As pessoas com DF devem ser informadas quanto aos cuidados preventivos das úlceras de perna. Essa enfermidade amplia a demanda por cuidados, gerando dependência quanto ao manejo diário dessas lesões, que permanecem por longos períodos ou nunca cicatrizam, interferindo no seu cotidiano.

Para Santos (2013), a criação de vínculos entre paciente, família e profissionais do centro de atendimento é essencial para a terapêutica. Infelizmente, devido às lacunas na formação e na qualificação permanente desses profissionais, a pessoa com úlcera de perna, que chega à unidade de saúde, é dirigida às salas de curativos para limpeza das feridas e, raras vezes, será alvo de uma consulta com abordagem integral.

Estudos revelam que, nas unidades de saúde, quem mais assiste às pessoas com úlceras crônicas são os profíssionais de nível médio, que ofertam medidas que se restringem a limpeza das feridas com solução físiológica $0,9 \%$, antissépticos e aplicação de pomadas (FONTES; GAMA, 2011).

De acordo com Manzini e Simonetti (2009), o enfermeiro, como integrante da equipe multiprofissional, desenvolve atividades de acompanhamento das pessoas com DF e feridas. Além de atuar como educador em saúde, esse profissional desenvolve a consulta de enfermagem. Ainda, segundo os autores, durante a consulta de uma pessoa adoecida, o enfermeiro realiza avaliação geral, que inclui aferição da pressão arterial (PA); verificação da 
altura, peso, investigação dos fatores de risco e hábitos de vida; orientação sobre a doença, levantamento de informações sobre uso regular de medicamentos prescritos e automedicação.

$\mathrm{Na}$ experiência da extensão universitária, durante a consulta de enfermagem à pessoa com DF e úlceras de perna, percebeu-se a importância em se priorizar o exame da pele e das escleróticas, em busca de sinais de desidratação e icterícia (devido à hemólise), pesquisa do histórico de estados gripais ou outras infecções recentes, pois essas situações apresentam relação direta com a hipóxia da pele e a possibilidade de piora da úlcera de perna, evidenciada por aumento do biofilme bacteriano, surgimento de material necrótico, relatos de aumento de dor no local e sua periferia, ou até mesmo o aumento no tamanho da lesão.

A consulta de enfermagem mostrou-se relevante, portanto, para o planejamento da assistência e foi implantada para subsidiar o cuidado oferecido às pessoas com DF que apresentavam úlceras de perna e buscavam curativos nas unidades de saúde, e fortalecer os vínculos com a equipe de Enfermagem, favorecendo a atenção integral.

Este relato de experiência tem por objetivo descrever a consulta de enfermagem às pessoas com úlceras de perna e DF, desenvolvida por discentes do curso de graduação em Enfermagem, bolsistas em atividades extensionistas no atendimento às pessoas com a enfermidade.

A extensão universitária constitui uma estratégia a fim de aproximar os sujeitos em formação da realidade concreta do mundo do trabalho. Para os futuros enfermeiros, a extensão é essencial para a construção de vínculos com a comunidade e o fortalecimento das relações entre profissionais e usuários dos serviços de saúde.

\section{METODOLOGIA}

A experiência aconteceu no âmbito das práticas de extensão universitária do "Projeto Pele Sã: estudos e práticas multidisciplinares de cuidados às pessoas acometidas ou sobre risco de desenvolver úlceras por pressão, e suas famílias atendidas no Hospital Geral Clériston Andrade (HGCA)", que envolve docentes e discentes da graduação em Enfermagem da Universidade Estadual de Feira de Santana (UEFS), no estado da Bahia.

São objetivos do projeto: levantar o perfil das pessoas acometidas por úlceras por pressão, hospitalizadas no HGCA; levantar o perfil das pessoas sob risco de desenvolver úlceras por pressão no HGCA, aplicando escalas preditivas; analisar o conhecimento sobre prevenção de úlceras das equipes envolvidas no cuidado de pessoas dependentes para o autocuidado no contexto do HGCA; qualificar os profissionais de saúde e discentes para avaliar o risco e cuidar de adultos e idosos com úlceras de diversas etiologias; analisar as práticas de prevenção e cuidado das pessoas com úlceras por pressão no contexto do HGCA.

Os primeiros contatos com pessoas com DF se deram por iniciativa de um dos membros da Associação Feirense de Pessoas com Doença Falciforme (AFADFAL), que procurou a equipe executora do projeto de extensão em busca de apoio para o cuidado às úlceras de perna. Assim, foram apoiados por pessoas vinculadas à AFADFAL, que, por meio de informações durante as reuniões, orientaram que os pacientes que possuíam úlceras de perna e seus familiares procurassem os profissionais de Enfermagem do "Projeto Pele Sã". 
Percebeu-se que as pessoas com DF e úlceras de pernas encontravam-se invisibilizadas nas unidades de saúde convencionais, por não existir um atendimento especializado e dirigido a elas, no que tange à realização da consulta de Enfermagem enfocada nas necessidades desse grupo específico. Assim, os discentes e docentes da UEFS realizaram uma busca ativa no atendimento a enfermos com feridas crônicas no ambulatório do HGCA e no Centro de Atenção a Pessoas com Diabetes e Hipertensão de Feira de Santana (CADH), visando identificá-las. Considerando que um dos objetivos do projeto é prover a qualificação de profissionais, o corpo docente capacitou enfermeiros, técnicos de enfermagem, discentes e outros docentes para cuidar de pessoas com úlceras crônicas e DF, com vistas a descentralizar o atendimento que se concentrava no HGCA.

A capacitação foi desenvolvida em três etapas. Na primeira, foram realizadas entrevistas com as pessoas atendidas, visando conhecer vivências e necessidades de cuidado. Os depoimentos foram colhidos pelos bolsistas e utilizados para sensibilizar toda equipe. Na segunda, processaram-se discussões teóricas acerca da doença falciforme e características das úlceras de perna secundárias à doença e rodas de conversas com debate sobre o conteúdo de artigos científicos acerca dos recursos curativos disponíveis para tratamento. Na terceira etapa, no ambulatório do HGCA, tiveram lugar atividades práticas de aplicação do instrumento de exame físico e anamnese, instalação de terapia compressiva e recursos de tratamento tópico das úlceras.

Optou-se pela busca ativa, porque a literatura aponta que a experiência do estigma vivenciada por adultos adoecidos com úlceras de perna, a vergonha em se expor publicamente (LACERDA et al., 2014), a longa e cansativa espera em salas de curativos e a baixa resolubilidade dos serviços tendem a desanimá-los a frequentarem os serviços de saúde, assim, eles acabam preferindo cuidar das suas úlceras em casa.

Durante doze meses, entre fevereiro de 2013 e fevereiro de 2014, foram diagnosticadas 20 pessoas com úlceras de perna e DF, motivando a criação de uma agenda específica para cuidá-las. Foram realizadas consultas de enfermagem nas próprias salas de curativos. Dado à natureza crônica e recidivante das úlceras, essas pessoas continuam sendo acompanhadas.

As consultas de enfermagem desenvolvidas pelos bolsistas em ambiente privativo contemplaram anamnese, exame físico e exame da ferida. Nessas oportunidades, os bolsistas aprendem a levantar dados a respeito do autocuidado, quando se investiga o passado de internamentos, transfusões sanguíneas, infecções e os tratamentos aos quais as pessoas já foram submetidas, o uso de hidroxiuréia, terapias coadjuvantes e soluções ou curativos que já foram experimentados.

Por meio da aplicação de um impresso elaborado pelos próprios bolsistas - produto de um trabalho de conclusão de curso - foram levantadas informações acerca da forma como a ferida iniciou, tempo de existência e idade em que ela se manifestou pela primeira vez, já que esse tipo de úlcera tende a recidivas frequentes.

$\mathrm{Na}$ avaliação física, os bolsistas mensuraram a circunferência da panturrilha, tornozelo e dorso do pé. No tocante à avaliação da úlcera, eles observaram características do leito, da pele perilesional, do exsudatos e sintomas relacionados (dor local, odor, ardor e ou câimbras), e a presença de pelos na pele adjacente. Todas essas características foram registradas no prontuário de cada paciente. Em seguida, mensuraram a extensão da úlcera e identificaram os diagnósticos de enfermagem. 
Durante o período de avaliação das pessoas com úlceras de perna e DF, os diagnósticos de enfermagem mais frequentes emitidos pelos bolsistas foram: a integridade tissular prejudicada, dor crônica, perfusão tissular periférica ineficaz, risco de infecção, excesso do volume de líquidos, alteração da autoimagem e baixa autoestima.

Posteriormente, os bolsistas elaboraram o plano de cuidados individualizado, que incluiu medidas de autocuidado, tais como: proteção da pele, para evitar trauma local; hidratação oral adequada; manutenção da pele lubrificada com emolientes; elevação de membros inferiores; e estimulação de exercícios. Por fim, aplicaram cuidados tópicos à úlcera, terapia compressiva com bota de Unna e realizaram encaminhamentos à terapia hiperbárica. Foram observadas redução do tamanho da úlcera, disposição para o autocuidado melhorada, adesão a medidas terapêuticas, redução da dor e melhora no padrão do sono.

A partir das atividades extensionistas do "Projeto Pele Sã", os adoecidos com DF e úlceras de perna foram inicialmente acolhidos e cuidados. Após a qualificação dos docentes, bolsistas e profissionais do Centro de Referência Municipal a Pessoas com Doença Falciforme de Feira de Santana (CRMPDF), os pacientes foram encaminhados para o referido centro.

\section{RESULTADOS E DISCUSSÃO}

A consulta de enfermagem é essencial para a promoção do autocuidado e o sucesso dos tratamentos instituídos em favor do bem-estar das pessoas. Recurso esse que proporciona, ao profissional, conhecer as práticas de cuidado adotadas pelos sujeitos; permite a detecção precoce de desvios e a negociação de saberes entre profissionais e usuários; e viabiliza o trabalho do enfermeiro durante o atendimento ao paciente, facilitando a identificação de problemas e as decisões a serem tomadas (CARVALHO et al., 2008).

Enquanto espaço de diálogo, a consulta de enfermagem é importante para que os pacientes adquiram conhecimentos necessários acerca de sua patologia, pois o sucesso, tanto no tratamento quanto na prevenção de complicações, depende dessa conscientização (TAVARES et al., 2010).

Durante as consultas, percebeu-se a aplicação de uma gama de recursos de terapia tópica de forma deturpada, por exemplo, o uso de pomadas em demasia, o que promove extravasamento sobre a periferia da úlcera, ampliando seu tamanho; o corte, visando economizar, de metade da faixa de compressão, aplicando-a somente no local, como se fosse uma terapia local; a prática de ressecar o leito da ferida, devido à crença de que, quando resseca, é sinal de melhora, mas, ao contrário, pode levá-la a planos mais profundos; a dobra das bandagens, para possibilitar o uso de sandálias de salto e disfarçar sua presença, provocando garroteamento do membro e piora da circulação; o uso de talco ou água sanitária para eliminar odores que resultam em manifestações alérgicas e irritativas, causando novas feridas; dentre outras.

Durante os cuidados, observou-se a constante maceração da pele íntegra da periferia da úlcera, queixas dos adoecidos quanto à dor intensa, ao prurido e ardência na pele, devido às dermatites e ao desconforto dos odores provocados por secreções.

A consulta de enfermagem se apresenta como espaço de escuta, constituindo-se, assim, numa oportunidade para o acolhimento e a escuta sensível de problemas vivenciados pelos sujeitos 
adoecidos. Estratégia, pois, que torna possível conhecer e compreender como as pessoas com úlceras de perna vivenciam seu cotidiano e enfrentam as adversidades impostas pela patologia e pelo tratamento a que se submetem.

Estudo de Lacerda et al. (2006) mostrou que as pessoas com úlceras de perna e DF padecem de dor que as impede de realizar as atividades cotidianas, necessitando de uma abordagem sensível por parte do profissional de saúde para ajudar no controle desse sintoma, além de apoiar a pessoa na adesão de medidas de autocuidado que evitem o surgimento de novas úlceras.

A ingestão de líquidos e a aplicação de emolientes na pele necessitam ser incentivadas durante as consultas, pois, com a pele seca, a pessoa tende a coçar, provocando pequenas fissuras que podem tornar-se úlceras. Os emolientes são emulsões compostas de lipídios, que têm a propriedade de amaciar e restaurar a elasticidade e homeostase da pele, além de evitar a perda transepidérmica de água. Os emolientes lubrificam e hidratam a pele, protegem a integridade do estrato córneo e da barreira cutânea, além de tratar a pele seca (FERNANDES; MACHADO; OLIVEIRA, 2011).

Durante as consultas, percebeu-se, na fala dos adoecidos, uma preocupação não somente em atingir a cicatrização, mas um temor quanto ao surgimento de novas úlceras, ao aumento do tamanho das já existentes e aos desconfortos gerados na pele periolesional. Assim, é importante que, durante as consultas de enfermagem, se faça um exame da periferia da ferida, devido ao surgimento de dermatites que tendem a provocar o aumento de tamanho da úlcera.

Segundo Abbade e Lastória (2006), as dermatites de contato ao entorno da úlcera de perna costumam ser pruriginosas e secundárias à sensibilização, em razão do uso prolongado de antibióticos tópicos (neomicina, sulfas, gentamicina, entre outros), lanolina e antissépticos (iodo-povidona). Outros pacientes podem desenvolver, também, dermatite irritativa ao exsudato da úlcera, por isso, durante a aplicação de curativos e terapia compressiva, um penso absorvente secundário é utilizado para conter as drenagens advindas das úlceras, e os adoecidos são orientados a trocá-lo diariamente (ABBADE; LASTÓRIA, 2006).

O uso da terapia compressiva, mediante aplicação da bota de Unna em pessoas com DF, se justifica por ela exercer efeitos sobre a estase venosa e sobre os tecidos, já que a contenção melhora a reabsorção dos capilares sanguíneos, diminui a complacência e melhora o trofismo tecidual (KIESKI; TURRA, 2012). A menor frequência de troca de curativos no uso dessa terapia evita a ida diária à unidade de saúde e confere ao paciente maior independência de cuidados. Observam-se, também, menos eventos dolorosos promovidos pela manipulação diária da ferida.

Contudo, a consulta de enfermagem é imprescindível para a segurança e o sucesso da terapia, visto que se faz necessária mensuração da perna, bem como das úlceras, para estabelecer parâmetros de comparação e inferir sobre a evolução dessas lesões e o progresso da terapia empregada. Devido à complexidade das úlceras de perna secundária a DF, é necessário o acompanhamento por uma equipe multiprofissional, a fim de oferecer um cuidado na sua totalidade, minimizando a sintomatologia da DF com consequente melhora das lesões (BAJAY; ARAÚJO, 2006).

Durante a evolução do tratamento das feridas, os sinais de piora ou recidivas podem surgir e devem ser vistos nas consultas de enfermagem, já que esses sinais estão diretamente relacionados ao estado geral de saúde da pessoa, o que requer a reavaliação integral na busca 
por ocorrências de estados gripais, infecções respiratórias ou urinárias, bem como a interrupção de terapia específica, como a hidroxiureia, que reflete sobre a perfusão periférica do oxigênio nos tecidos cutâneos e repercute sobre condição das úlceras em cicatrização.

Sendo o enfermeiro um dos principais responsáveis pelo tratamento dessas feridas, esse profissional deve explicar e incentivar os pacientes durante as consultas de enfermagem quanto à importância do seguimento terapêutico (MARTINS et al., 2013). Além disso, ao identificar e avaliar sinais clínicos de piora da úlcera, ele deve reavaliar o estado geral da pessoa; articular, com os demais profissionais, a realização de consultas especializadas; e encaminhar a pessoa para reavaliação médica, terapias adjuvantes e ou atendimento de urgência.

Por não alcançar a cicatrização das lesões em um curto espaço de tempo, a terapêutica, muitas vezes, é interrompida pelo não comparecimento nas consultas de enfermagem, fato influenciado pela situação socioeconômica, pela baixa renda e por fatores limitantes para inserção no mercado de trabalho, já que as idas constantes às unidades de saúde tornam-se onerosas (BAJAY; ARAÚJO, 2006).

A educação para o autocuidado foi realizada pelos bolsistas durante as consultas. Segundo Kikuchi (2007), essa medida ajuda pessoas com DF a compreender por que devem incorporar no seu cotidiano hábitos que venham a prevenir ou amenizar as complicações da doença. Quanto às lesões de membros inferiores (MMII), os bolsistas informaram sobre a necessidade de evitar trauma local, uso de sapatos que se ajustem adequadamente ao pé, uso de repelentes para evitar picadas de insetos e a não utilização das veias da perna para terapia intravenosa, visando reduzir a chance de desenvolvimento de uma lesão crônica. Também orientaram a tratar os traumas logo após o seu surgimento e, às pessoas com história de úlceras anteriores, recomendaram o uso de meias elásticas até acima do joelho. Segundo Paladino (2007), a prática de tais medidas auxilia, de forma eficaz, na prevenção de recidivas de úlceras falciformes, a começar pela adesão de medidas preventivas diárias e regulares.

\section{CONSIDERAÇÕES FINAIS}

Este relato de experiência descreveu a consulta de enfermagem a pessoas com úlceras de perna e doença falciforme, desenvolvida por discentes do curso de graduação em Enfermagem, em atividades de extensão.

A experiência possibilitou a qualificação de profissionais da rede e das bolsistas do projeto. As discentes tiveram a oportunidade de reconhecer a importância da avaliação geral da pessoa que apresenta uma úlcera de perna, compreendendo que a presença, permanência ou recidiva da lesão não está relacionada tão somente ao emprego de medidas tópicas de cuidado. Compreenderam, também, que as medidas tópicas, como limpeza e curativos, geram desconfortos, e estes podem ser reduzidos ou evitados, quando adotado, por exemplo, o uso de analgésico trinta minutos antes do curativo, anestésico tópico e malhas não aderentes à base de ácidos graxos essenciais para minimizar a dor desses pacientes.

As medidas sistematizadas por meio da consulta de enfermagem e desenvolvidas pelos bolsistas, nesta experiência, qualificaram o cuidado às pessoas com úlcera de perna e DF, resultando em conforto e melhoria na qualidade de vida dessas pessoas. Tais medidas 
contribuíram também para mudanças na rede de atenção às pessoas com DF, possibilitando a criação de espaço especializado de cuidado a uma das complicações da doença de maior impacto sobre o cotidiano dos adoecidos. Além disso, revelaram a potencialidade das atividades da extensão universitária para a mudança da realidade de grupos vulneráveis.

As práticas extensionistas iniciadas no "Projeto Pele Sã" deram lugar à abertura de um consultório de atendimento a pessoas com úlceras de perna e DF, no CRMPDF, e à criação de um novo projeto de extensão.

Atualmente, essas pessoas são atendidas de forma integral por uma equipe multiprofissional, composta por enfermeiros, médico, nutricionista, assistente social, fisioterapeuta e psicólogo, além de docentes e bolsistas de extensão.

\section{REFERÊNCIAS}

ABBADE, L. P. F.; LASTÓRIA, S. Abordagem de pacientes com úlcera da perna de etiologia venosa. An. Bras. Dermatol, Rio de Janeiro, v. 81, n. 6, p. 509-522. 2006.

BRASIL. Ministério da Saúde. Departamento de Atenção Especializada. Manual de condutas básicas na doença falciforme. Brasília, DF: Editora do Ministério da Saúde, 2006.

BAJAY, H. M.; ARAÚJO, I. E. M. Validação e confiabilidade de um instrumento de avaliação de feridas. Acta Paul. Enferm., São Paulo, v. 19, n. 3, p. 290-295, jul.-set. 2006.

CARVALHO, A. L. S. et al. Avaliação dos registros das consultas de enfermagem em ginecologia. Rev. Eletrônica Enferm., Goiânia, v. 10, n. 2, p. 472-483, 2008.

FERNANDES, J. D.; MACHADO, M. C. R.; OLIVEIRA, Z. N. P. Prevenção e cuidados com a pele da criança e do recém-nascido. An. Bras. Dermatol., Rio de Janeiro, v. 86, n. 1, fev. 2011 .

FONTES, M. M. A.; GAMA, F. N. Análise da técnica do curativo no tratamento de feridas em unidades de atenção primária à saúde no município de Coronel Fabriciano-MG. Revista Enfermagem Integrada, Ipatinga, v. 4, n. 2, nov.-dez. 2011.

KIESKI, G.; TURRA, K, T. Sistematização da assistência de enfermagem na terapia compressiva: uma possibilidade terapêutica. Revista Eletrônica da Faculdade Evangélica do Paraná, Curitiba, v. 2, n. 4, p. 19-29, out.-dez. 2012.

KIKUCHI, B. A. Assistência de enfermagem na doença falciforme nos serviços de atenção básica. Rev. Bras. Hematol. Hemoter., São José do Rio Preto, v. 29, n. 3, p. 331-338, 2007.

LACERDA, E. P. et al. Atuação da enfermagem no tratamento com oxigenoterapia hiperbárica. Rev. Latino-Am. Enfermagem, Ribeirão Preto, v.14, n. 1, p. 118-123, jan.-fev. 2006.

LACERDA, F. K. L. et al. Women with sickle anemia living with leg ulcers and pain. Rev. Enferm UFPE, Recife, v. 8, n.7, p. 2054-2060, jul. 2014. 
MANZINI, F. C.; SIMONETTI, J. P. Consulta de enfermagem aplicada a clientes portadores de hipertensão arterial: uso da teoria do autocuidado de orem. Rev. Latino-Am. Enfermagem, Ribeirão Preto, v.17, n.1, p. 113-119, 2009.

MARTINS, A. et al. O autocuidado para o tratamento de úlcera de perna falciforme: orientações de enfermagem. Esc. Anna Nery, Rio de Janeiro, v.17 n. 4, p. 755-763, 2013.

PALADINO, S. F. Úlceras de membros inferiores na anemia falciforme. Rev. Bras. Hematol. Hemoter, São José do Rio Preto, v. 29, n. 3, p. 288-290, jul.-set. 2007.

SANTOS, I. V. A. Características das úlceras de membros inferiores em pessoas com doença falciforme. 2013. 64f. Monografia (Bacharelado em Enfermagem) - Universidade Estadual de Feira de Santana, Feira de Santana, 2013.

TAVARES, D. M. S. et al. Diabetes mellitus: fatores de risco, ocorrência e cuidados entre trabalhadores de enfermagem. Acta Paulista de Enfermagem, São Paulo, v. 23, n. 5, p.671$676,2010$.

THOMAS, M. L. Histórico e cuidados aos pacientes com distúrbios hematológicos. In: SMELTZER, S. C. et al. Brunner \& Suddarth: tratado de enfermagem medico-cirúrgica. 11. ed. Rio de Janeiro: Guanabara Koogan, 2009.

Submetido em 6 de agosto de 2014.

Aprovado em 26 de agosto de 2014. 